\title{
Finite element analysis of newly introduced plates for mandibular condyle neck fracture treatment by open reduction and rigid fixation
}

\section{Metoda elementów skończonych w ocenie nowo wprowadzanych płytek do ograniczenia otwierania i sztywnej stabilizacji w leczeniu złamania szyjki wyrostka kłykciowego żuchwy}

\author{
Marcin Kozakiewicz',A,C,D,F, Jacek Świniarski2,A-C,E,F \\ ${ }^{1}$ Clinic and Department of Maxillofacial Surgery, Medical University of Lodz, Łódź, Poland \\ ${ }^{2}$ Department of Strength of Materials and Structures, Faculty of Mechanical Engineering, Lodz University of Technology, Poland \\ A - research concept and design; B - collection and/or assembly of data; C - data analysis and interpretation; \\ $D$ - writing the article; $E$ - critical revision of the article; $F$ - final approval of the article
}

\section{Address for correspondence \\ Marcin Kozakiewicz}

E-mai: marcin.kozakiewicz@umed.lodz.pl

\section{Funding sources}

Grant of the Medical University of Lodz,

Poland: 1.503/5-061-02/503-51-001

Conflict of interest

None declared

Received on September 9, 2017

Reviewed on 0ctober 7, 2017

Accepted on October 22, 2017

DOI

$10.17219 / \mathrm{dmp} / 78913$

Copyright

@ 2017 by Wroclaw Medical University

and Polish Dental Society

This is an article distributed under the terms of the

Creative Commons Attribution Non-Commercial License

(http://creativecommons.org/licenses/by-nc-nd/4.0/)

\begin{abstract}
Background. Fractures of the mandibular condyle have been a topic of controversy and discussion in the area of maxillofacial trauma for many years. Any treatment should provide accurate reduction and stability of fractured bony fragments to enable further uncomplicated mandibular function. Recently, 2 novel plates were introduced: strut and rhombus.

Objectives. To compare the newly introduced plates for mandibular condyle neck fracture treatment.

Material and methods. A total of 6 variants of fixing by 5 screws were tested by finite element analysis: strut plate in the normal position (T1), strut plate in an inverted position (T2), rhombus plate with 2 screws positioned close to the lower border sliding middle holes (T3), rhombus one with a mesial screw positioned close to the upper border of the sliding hole and distal screw positioned close to the lower border of the sliding hole (T4), rhombus one with both screws in sliding holes positioned close to the upper border of the holes (T5), and modified rhombus plate where all holes are round (T6). Equivalent maximal stress in the fixing material and relative displacement in the fracture line were calculated, and the influence of the act of mastication on fatigue failure was evaluated.
\end{abstract}

Results. The position of the plate and location of the fixing screws are crucial for stabilization of the reduced bone fragments. Any adjustments of these 2 plates by bending, flattening or cutting are unsafe. Mean relative displacement in the fracture line and equivalent maximal stress were T1: $958 \pm 312 \mu \mathrm{m}$ (the

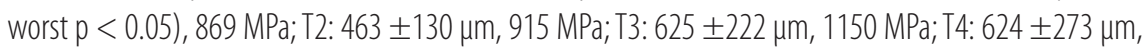

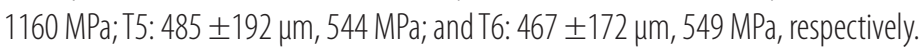

Conclusions. It should be noted, comparing both plates, that the rhombus plate equipped only with round holes (not sliding holes) presented its superiority within this pairing. It is mechanically relatively resistant and relatively durable in spite of the design being only partially according to compression and traction force propagation in the mandibular condyle.

Key words: treatment, finite element method, fracture, mandibular condyle neck, fixing material

Słowa kluczowe: leczenie, metoda elementów skończonych, złamanie, szyjka wyrostka kłykciowego żuchwy, materiał zespalający 
Fractures of the mandibular condyle have been a topic of controversy and discussion in the area of maxillofacial trauma for many years. For decades, closed reduction has been the preferred method, but it requires intermaxillary fixation, followed by functional therapy. ${ }^{1}$ Only in the pediatric population is it the gold standard. Any treatment should provide accurate reduction and stability of fractured bony fragments to enable further uncomplicated mandibular function. There is now greater consensus about performing open reduction, considering the better results. $^{2-4}$

Recently, 2 manufactures have introduced new plates (Table 1): a strut plate by DePuy Synthes ${ }^{5}$ and a rhombus by KLS Martin. ${ }^{6}$ The strut plate is a very innovative concept, taking into account force distribution in the condyle region. The manufacturer reports that 1 ) the small size allows placement using multiple surgical approaches such as intraoral, retromandibular, submandibular and preauricular, 2) for placement, the straight 3-hole segment should be nearly parallel to the posterior border and aligned with the condylar head, 3) it is adjustable to fit patient anatomy (superior holes can be bent independently), and 4) the middle hole can be left empty for more "vertical" fractures. On the other hand, the rhombus is a typical development of the stiff triangle plate. The manufacturer explains that the most distinctive features of the Rhombus 3D Condylar Fracture Plate are: 1) it can be used for the surgical treatment of deep, medium and high condylar process fractures, 2) the rhombus shape of the plate provides for optimal transmission of the tensile and compressive forces present in the mandible, and 3) closely positioned screw holes in the proximal part of the plate allow secure placement of the osteosynthesis screws even under difficult spatial conditions.

The objective of this study is to compare the newlyintroduced plates for mandibular condyle neck fracture treatment.

\section{Material and methods}

\section{The plates}

The DePuy Synthes strut plate (art. no. 04.503.832) was compared to the KLS Martin rhombus 3D plate (art. no. 25-285-05-09), both 5-hole condylar plates (Table 1). The locking screw system was assumed. All holes were used to fix the plate by screws. The strut plate was investigated in 2 positions: the one recommended by manufacturer and upside-down. The rhombus plate was tested in 4 configurations depending on the arrangement of the screw positioning: position $1-2$ screws (i.e. screw no. 3 and no. 4) are positioned close to the lower border oval holes (typical clinical fixation which is recommended by the manufacturer, ref 90-131-99-10), position 2
Table 1. Basic features of compared plates. Numbers in rhombus plate layout are chronological standard sequence of screw fixing according to manufacturer

\begin{tabular}{|c|c|c|}
\hline & Strut plate & Rhombus plate \\
\hline Layout & & \\
\hline Height & $28 \mathrm{~mm}$ & $20 \mathrm{~mm}$ \\
\hline Width & $14 \mathrm{~mm}$ & $13 \mathrm{~mm}$ \\
\hline Thickness & $1 \mathrm{~mm}$ & $1 \mathrm{~mm}$ \\
\hline Dedicated screws & $2.0 \mathrm{~mm}$ & $2.0 \mathrm{~mm}$ \\
\hline Number of holes & 5 & 5 \\
\hline Side dedication & yes (right-side presented) & no \\
\hline Pre-bent & convex & plain \\
\hline
\end{tabular}

- the mesial screw (screw no. 4) positioned close to the upper border of the oval hole and the distal screw (screw no. 3) positioned closed to the lower border of the oval hole, position 3 - both crews in the oval holes positioned close to the upper border of the holes (opposite to the typical clinical fixation), position 4 - a modified rhombus plate where all the holes are round (a design close to the KLS Martin angle-stable, locking plate).

The clinical protocol considered did not apply post-operational maxillo-mandibular fixation.

\section{Material properties}

Material properties of the titanium alloy Ti-6Al-4V grade 5 were applied in this study. There were: Young's modulus $104 \mathrm{GPa}$, Poisson coefficient 0.3, yield stress 934 $\mathrm{MPa}$, ultimate tensile stress $1650 \mathrm{MPa}$, and elongation to break approximately $10 \%$. Plastic modulus $(\mathrm{Ep}=1040 \mathrm{MPa})$ was used in the nonlinear calculations (a plastic modulus in engineering practice is used as hundredfold smaller than Young's modulus). The assessment of fatigue strength was adapted to the maxillofacial situation. The authors approximated the number of mastication cycles during a 6 -week healing period (42 days). It was evaluated that 5 series, each a 40 -bite action per day (i.e. 5 short meals), gave $200 \times 42=8400$ evolutions per healing period (approximately $10^{5}$ ). Later calculations were based on the study by Pekedis \& Yildiz, $2011 .{ }^{7}$

\section{Finite element analysis}

For the boundary conditions, ${ }^{8}$ the incisors were fixed in $3 \mathrm{D}$ coordinates, and the condyle could translate and rotate on the plane surface of a support. The load application was for a mouth closing up to $5 \mathrm{~mm}$ on the incisors. It is the most critical situation in the condylar 
processes. 9 The muscular functions applied were similar to those used previously ${ }^{8,10,11}$ and 5 pairs of gross muscles/actions were modelled: deep masseter (vector: $\mathrm{X}=7.78 \mathrm{~N}, \mathrm{Y}=127.23 \mathrm{~N}, \mathrm{Z}=22.68 \mathrm{~N}$ ), superficial masseter $(X=12.87 \mathrm{~N}, \mathrm{Y}=183.50 \mathrm{~N}, \mathrm{Z}=12.11 \mathrm{~N})$, medial pterygoid $(X=140.38 \mathrm{~N}, \mathrm{Y}=237.80 \mathrm{~N}, \mathrm{Z}=-77.30 \mathrm{~N}$ ), temporalis $(\mathrm{X}=0.06 \mathrm{~N}, \mathrm{Y}=0.37 \mathrm{~N}, \mathrm{Z}=-0.13 \mathrm{~N})$, and medial temporal $(X=0.97 \mathrm{~N}, \mathrm{Y}=5.68 \mathrm{~N}, \mathrm{Z}=-7.44 \mathrm{~N})$. The suprahyoid muscles were omitted due to their lack of action during mouth closing. The finite element model (FEM) used in the present study was composed of tetrahedral linear elements with 4 nodes and 5,200,000 degrees of freedom (DOF). The constructed model had not dentition because the presence of teeth has a marginal influence on the biomechanics and behavior of the mandibular condyles. ${ }^{11,12}$ The Ansys R14.5 program (Ansys Inc., Canonsburg, Pennsylvania, USA) was used for FEM calculation.

The mandible cortical bone layer was considered to have a Young's modulus of $14.7 \mathrm{GPa}$ and a Poisson coefficient of 0.3 , similar to models used previously. Cancellous bone Youngs modulus was used as 1.4 GPa. The width of the fracture line after open reduction was established at $0.32 \mathrm{~mm} .^{8}$ The plate was applied to the right side of the mandible. The implant position with respect to the mandible was defined by the level of fracture. The middle condylar neck fracture was chosen to test the plates, because it was impossible to utilize these plates for high condylar neck fracture treatment. ${ }^{16}$ To simulate the behavior of the screws, they were considered to be completely surrounded by cortical bone. The screw-implant contact was modelled as a touching contact situation. No contact between the implant and bone $(0.3 \mathrm{~mm}$ distance) was modelled. This lack of contact was important for the test of the plates as a load bearing device. Stress and displacement in the fracture line were analyzed on the external surface of the mandible and plates. ${ }^{8}$
Nonlinear calculations estimated on the basis of plastic modulus (Young's modulus to yield point, and plastic modulus beyond it) were applied in the models where maximal equivalent stress highly exceed yield stress (i.e. the rhombus plate with screw position 1 and 2).

\section{Statistical analysis}

ANOVA was applied to check which plate position generated the lowest relative movement during loading of the mandible. Statgraphics Centurion XVI (Statpoint Technologies, Inc., Warrenton, Virginia, USA) was used and statistical significance was indicated as $\mathrm{p}<0.05$.

\section{Results}

The calculated results are presented in Fig. 1-5 (displacement and stress) and Table 2 (relative movement in fracture line - positive value means extension traction). The strut plate tested in the normal position, i.e. positioned according to the manufacture's recommendation, is presented in Fig. 1. Maximal stress was $\sigma_{\text {red }}=869 \mathrm{MPa}$. There are 5 dangerous regions due to exceeding the maximal equivalent stress on the bone-facing side of the plate. The strut plate in the inverted position, i.e. positioned upside-down, is presented in Fig. 2. Maximal equivalent stress is $915 \mathrm{MPa}$. There are 2 dangerous regions due to exceeding the maximal equivalent stress on the bone-facing side of the plate in the posterior region, including 1 penetrating entirely through the plate - an evident break risk in the posterior part of the plate.

Two rhombus plate fixations were calculated in a nonlinear way (Fig. 3 and 4), based on the plastic modulus beyond the yield stress. Screw position 1 (Fig. 3) still revealed a high level of equivalent stress $-\sigma_{\max \text { red }}=1155 \mathrm{MPa}-$ and a series of risky sites of deformation. These were lo-

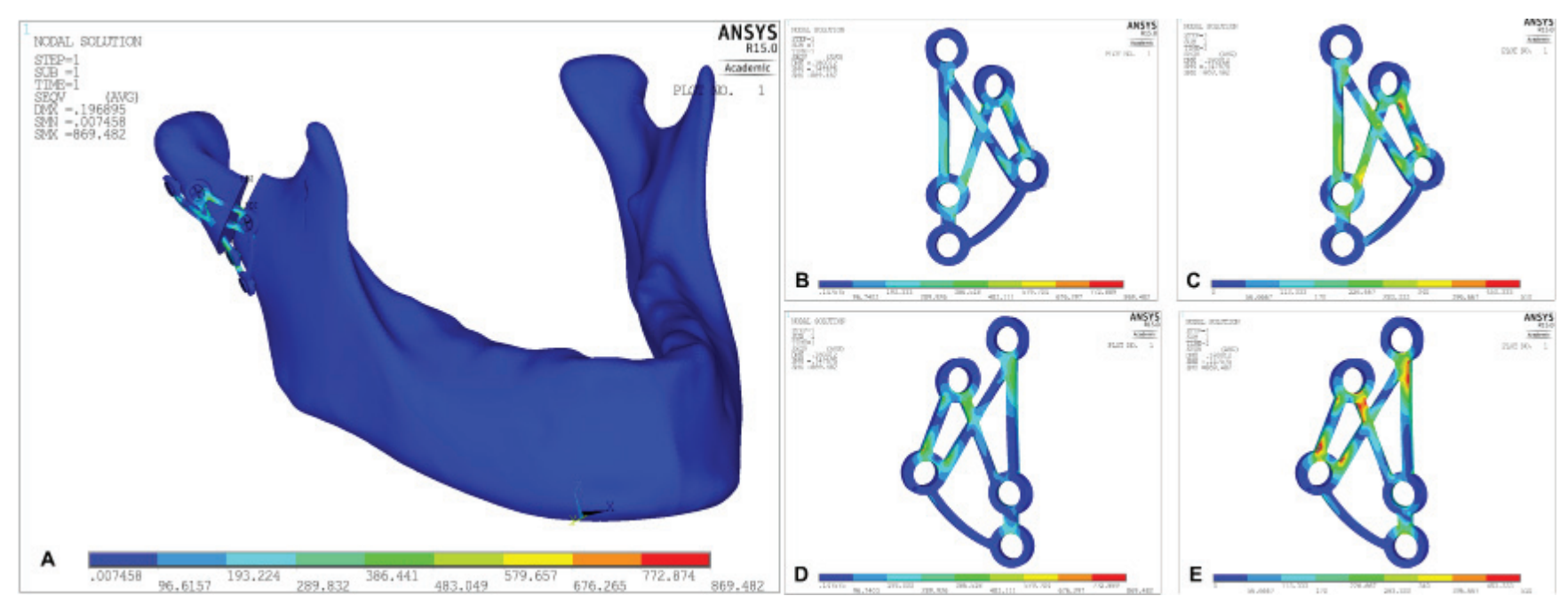

Fig. 1. Strut plate finite element analysis in the normal position, i.e. positioned according to the manufacturer recommendation.

A. Displacement of the bone fragment after ORIF is overscaled to improve the visualization. The bottom scale shows equivalent stress (maximal stress is $\sigma_{\text {red }}=869 \mathrm{MPa}$ ). B. Outer surface of the plate. C. Outer surface of the plate in a scale limited up to the fatigue failure stress for titanium alloy grade 5, i.e. $510 \mathrm{MPa}$. D. Bone-facing surface of the plate. E. Bone-facing surface of the plate in a scale limited up to fatigue failure stress.

There are 5 dangerous regions due to exceeding the maximal equivalent stress on the bone-facing side of the plate. 


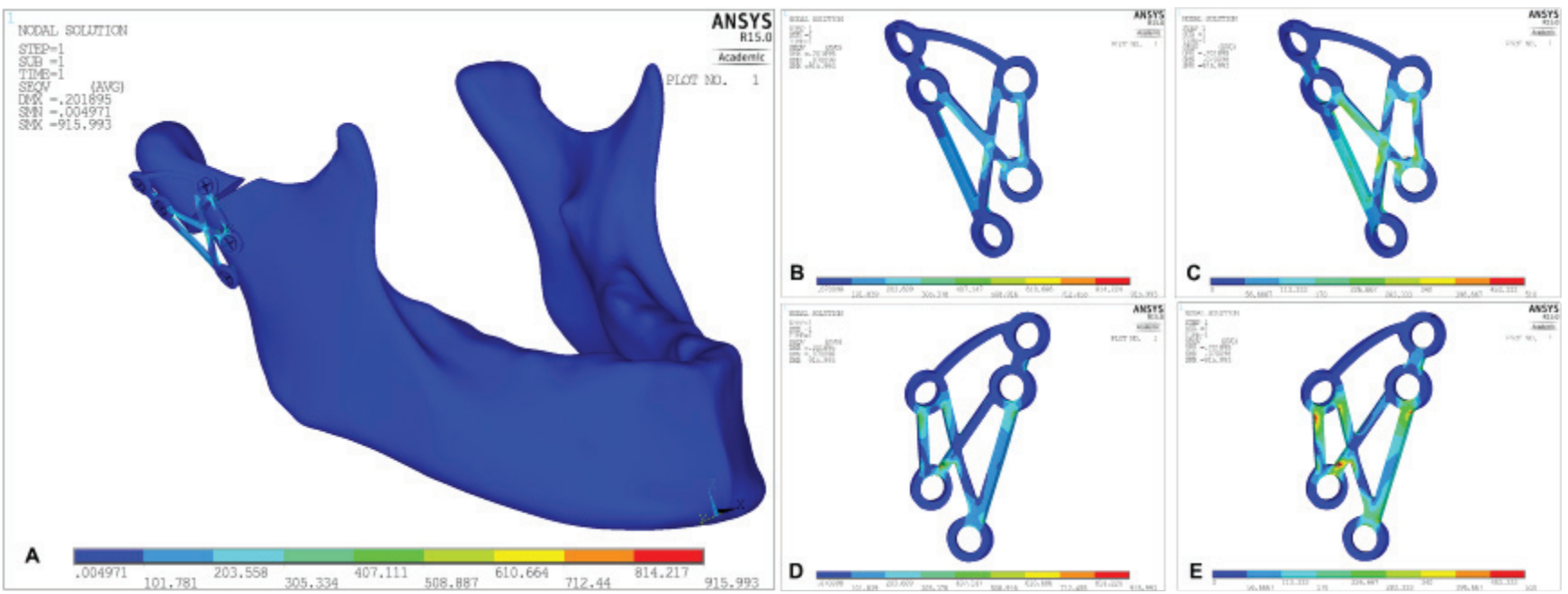

Fig. 2. Strut plate finite element analysis in the inverted position, i.e. positioned upside-down.

A. Displacement of the bone fragment after ORIF is overscaled to improve the visualization. The bottom scale shows equivalent stress (maximal stress is $\sigma_{\text {red }}=915 \mathrm{MPa}$ ). B. Outer surface of the plate. C. Outer surface of the plate in scale limited up to fatigue failure stress for titanium alloy grade 5, i.e. $510 \mathrm{MPa}$. D. Bone-facing surface of the plate. E. Bone-facing surface of the plate in scale limited up to fatigue failure stress.

There are 2 dangerous regions due to exceeding the maximal equivalent stress on the bone-facing side of the plate in the posterior region including 1 penetrating entirely through the plate. Evident break risk in the posterior part of the plate.

cated around screw/hole no. 3 and 4 ( $856 \mathrm{MPa})$. As far as the second modality was concerned: in position 2 (Fig. 4), the equivalent stress around the modified screw location no. 4 had been reduced below fatigue failure stress (i.e. below $510 \mathrm{MPa}$ ). For only the plate, it was $\sigma_{\max \text { red }}=973 \mathrm{MPa}$. This was contrary to the unmodified screw/hole no. 3 , where 4 fatigue failure stress risk regions were still observed. Maximum stress for the whole fixing material was $\sigma_{\max \text { red }}=1160 \mathrm{MPa}$, for the plate it was $892 \mathrm{MPa}$, and for the screws, $989 \mathrm{MPa}$ (Fig. 4).
The rhombus 3D plate with screw position 1, i.e. 2 screws positioned close to the lower border of the sliding (oval) holes, is presented in Fig. 3. Four dangerous regions were observed in the bone-facing side and 3 of them were visible on the outer side of the plate - break risk in the posterior part of the plate. The problem of the plate with the screw position recommended by the manufacturer is the chamfer of sliding holes, because the chamfer head of the screw can slip outside of the hole edge during loading. The rhombus $3 \mathrm{D}$ plate with screw position 2, i.e.
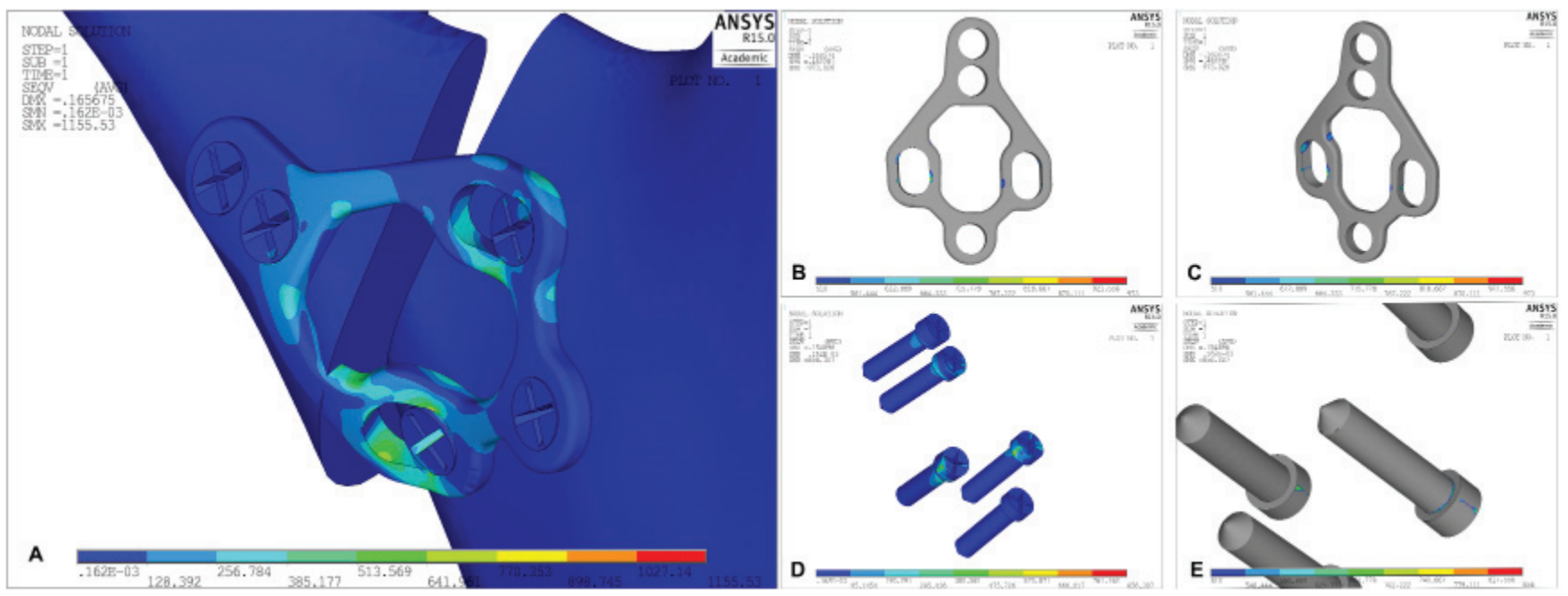

Fig. 3. Rhombus 3D plate finite element analysis with screw position 1, i.e. 2 screws are positioned close to the lower border of sliding (oval) holes. A. Displacement of the bone fragment after ORIF is overscaled to improve the visualization. The bottom scale shows equivalent stress (maximal stress in the plate is $\sigma_{\text {red }}=1155 \mathrm{MPa}$ ). Images $\mathrm{B}, \mathrm{C}$ and $\mathrm{E}$ present regions of stress over the fatigue failure stress (the fatigue failure stress of titanium alloy grade 5 is $510 \mathrm{MPa}$, and yield stress is $934 \mathrm{MPa}$ ).

Seven regions have fatigue failure stress risk around hole no. 3 ( 4 risk regions) and 4 (3 risk regions). Note (B, C), there are linear entire high stress concentration regions corresponding to the screw head thread's last contact to the plate in hole 3 and 4 (Table 1). Similar linear risky regions are in screw heads (D, E). They are the possible sites of the slipping of the screw head out of the plate hole.

The small plate has a low stiffness (high displacements in the fissure line) as screws are located according to producer requirements. The maximal stress in the plate is between the screws and the plate in connection sites on the edge of the screw. It creates local failure on the plate surface, and the fatigue destruction of the fixing material can begin at that place. 


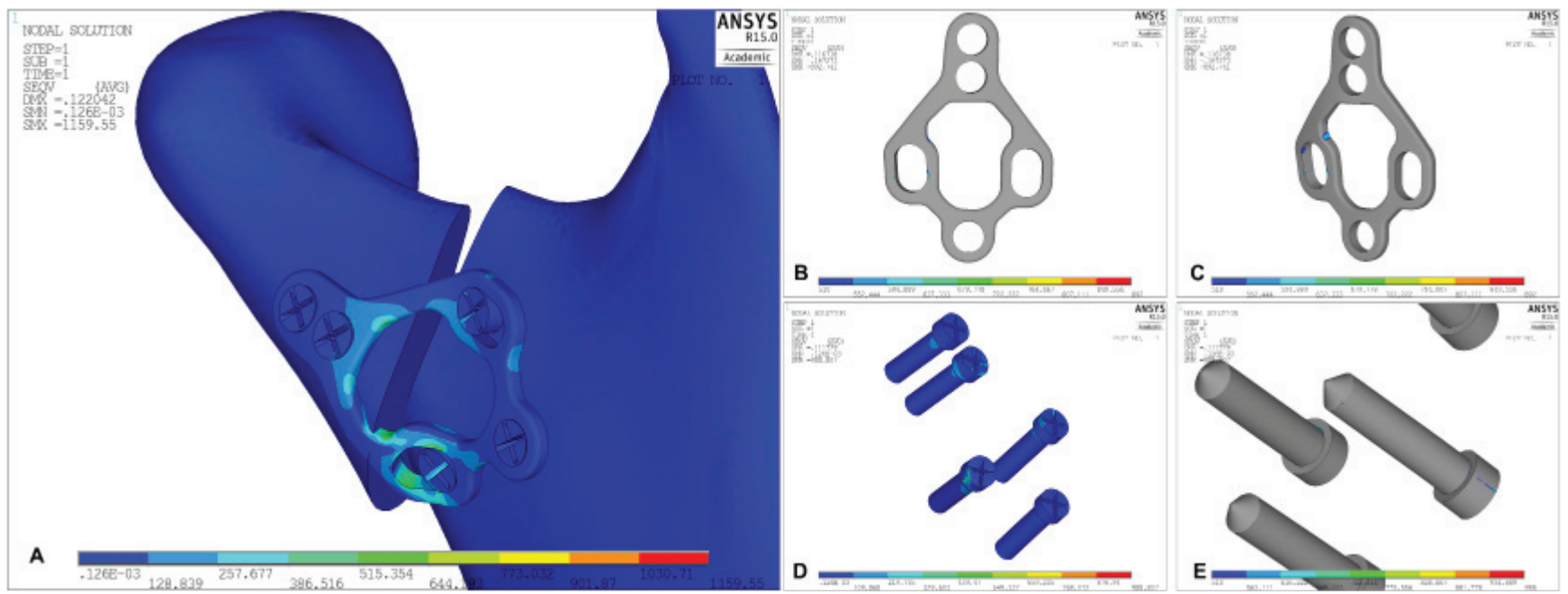

Fig. 4. Rhombus 3D plate finite element analysis with screw position 2, i.e. the mesial screw positioned close to the upper border of the sliding hole and the distal screw positioned close to the lower border of the sliding (oval) hole.

A. Displacement of the bone fragment after ORIF is overscaled to improve the visualization. The bottom scale shows equivalent stress (maximal stress is $\sigma_{\text {red }}=1160$ MPa). Images $\mathrm{B}, \mathrm{C}$ and $\mathrm{E}$ present regions of stress over the fatigue failure stress (fatigue failure stress of titanium alloy grade 5 is $510 \mathrm{MPa}$, and yield stress is $934 \mathrm{MPa}$ ). Four fatigue failure stress risk regions are around hole no. 3 (Table 1) where the fixing screw is located in the lower position (B, C). It is a typical clinical choice for screw location, but the worst one from a biomechanical point of view. Decreased stress in screw head no. 4 due to correction of the position to more upper. The linear area of fatigue failure stress lasts in the head screws no. 3 (D, E).

The change of position of one screw does not improve the stability of bone fragments. It improves mechanical conditions in the anterior part of the plate but deteriorates in the posterior aspect.

the mesial screw positioned close to the upper border of the sliding hole and the distal screw positioned closed to the lower border of the sliding (oval) hole, is presented in Fig. 4. High maximal stress in the plate is the result of the sliding holes, leading to weakness of the plate construction. There are 3 potential places for the plate to crack in the region of the distal sliding hole (hole no. 3, Table 1) and 2 additionally in the upper connecting arm of the plate. The maximal stress was observed in the fixing screw in sliding hole no. 3 . Three dangerous crack regions are around both lower holes, together with 2 regions in the upper part of the plate and 1 just below the head of the posterior screw in hole no. 3. The rhombus 3D plate with screw position 3, i.e. both screws in sliding holes positioned close to the upper border of the holes, is presented in Fig. 5. The maximal stress was $\sigma_{\max \text { red }}=544 \mathrm{MPa}$, and only 1 dangerous region for cracking was located in the anterior upper connecting arm. Maximal stress in the screws was $740 \mathrm{MPa}$. The modified rhombus 3D plate with screw position 4, i.e. all holes are round (a design

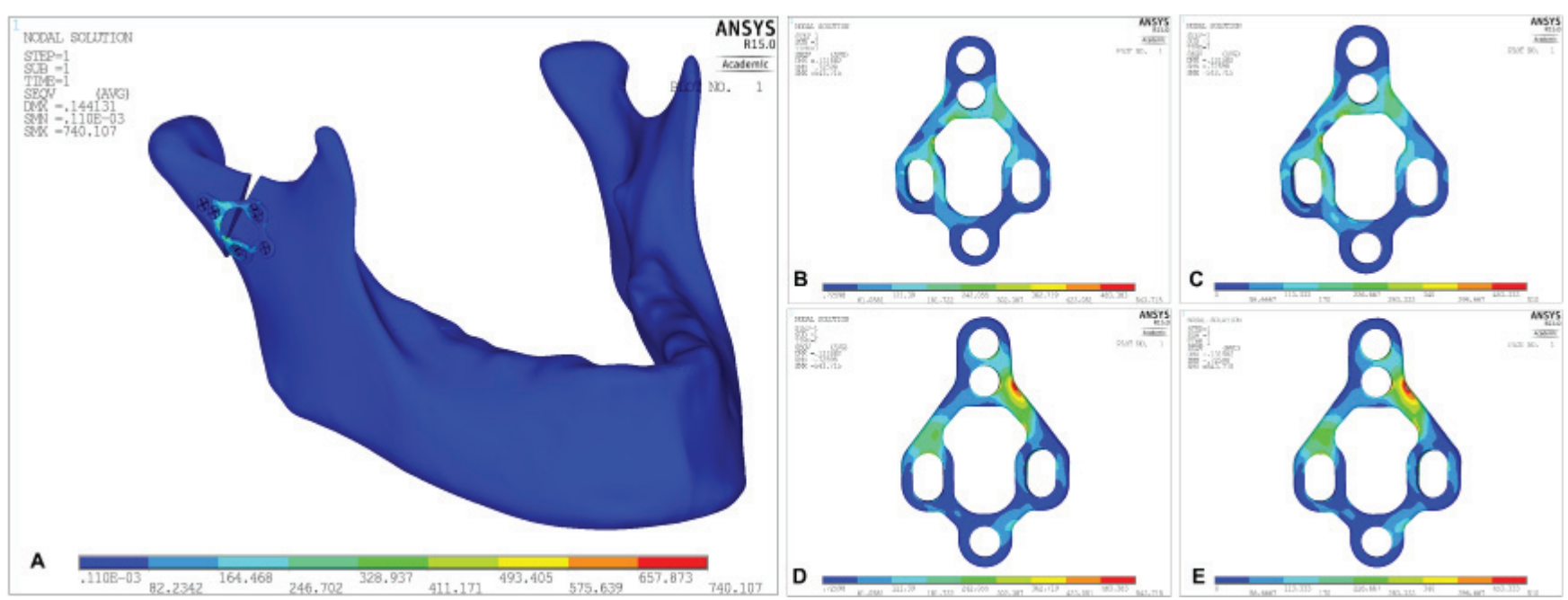

Fig. 5. Rhombus 3D plate finite element analysis with screw position 3, i.e. both screws in sliding holes positioned close to the upper border of the holes. A. Displacement of the bone fragment after ORIF is overscaled to improve the visualization. The bottom scale shows equivalent stress (maximal stress is $\sigma_{\text {red }}=544 \mathrm{MPa}$ ). B. Outer surface of the plate. C. Outer surface of the plate in scale limited up to fatigue failure stress for titanium alloy grade 5, i.e. 510 MPa. D. Bone-facing surface of the plate. E. Bone-facing surface of the plate in scale limited up to fatigue failure stress. One dangerous region for cracking located in the anterior upper connecting arm.

The proposed new screw positions improve the stability of the bone fragments. The point stresses are at limited range together with the smaller displacement of the bone fragments 


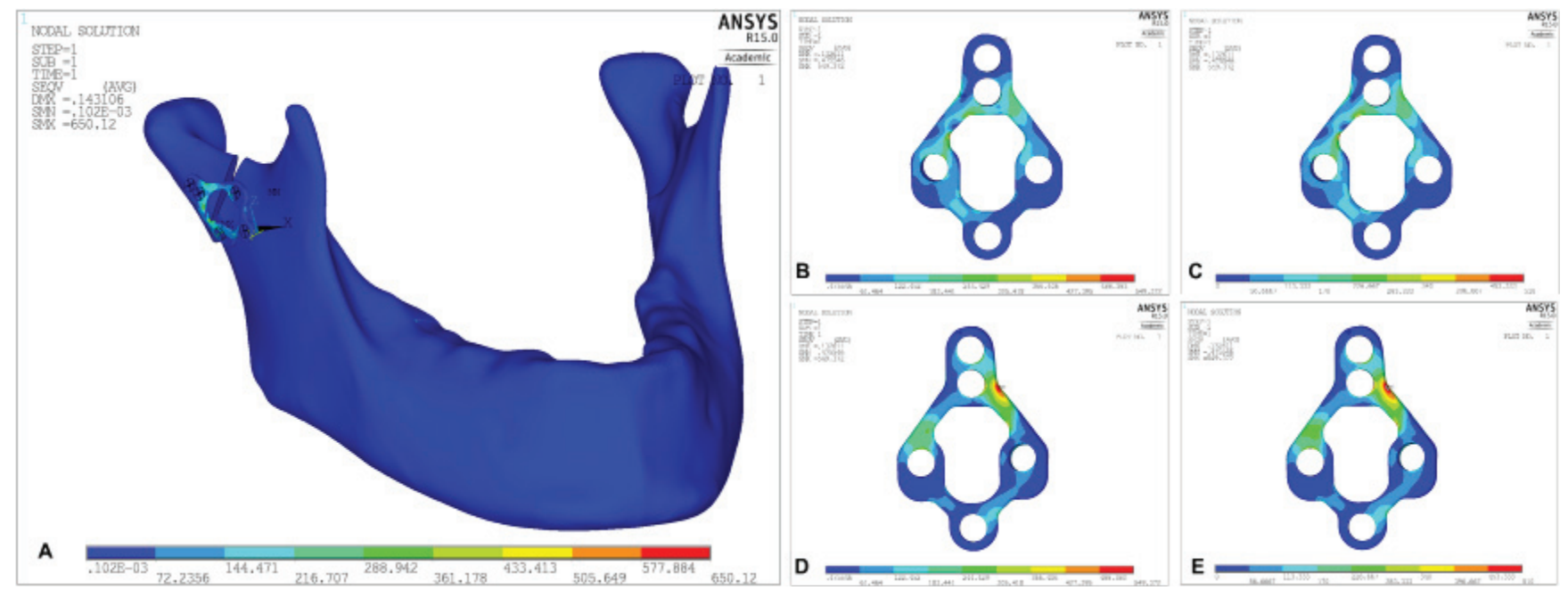

Fig. 6. Modified rhombus 3D plate finite element analysis with screw position 4, i.e. all holes are round.

A. Displacement of the bone fragment after ORIF is overscaled to improve the visualization. The bottom scale shows equivalent stress (maximal stress is $\sigma_{\text {red }}=549 \mathrm{MPa}$ ). B. Outer surface of the plate. C. Outer surface of the plate in scale limited up to fatigue failure stress for titanium alloy grade 5, i.e. 510 MPa. D. Bone-facing surface of the plate. E. Bone-facing surface of the plate in scale limited up to fatigue failure stress. There is 1 dangerous potential region (on the bone-facing side of the plate) of initiation of fatigue failure near upper hole no.1 (Table 1).

The general biomechanical conditions are the same as in Figure 5, but the stress in the material of the plate is the lowest in the whole experiment. The maximal stress is as low as at an A-shape condylar plate ${ }^{8}$ but the displacement in the fracture line is 3 times smaller in the ACP case.

close to the KLS Martin angle-stable locking plate, art. no. 25-28-05-09), is presented in Fig. 6. Maximal stress was $\sigma_{\text {max red }}=549 \mathrm{MPa}$. There is 1 dangerous region (in the bone-facing side of the plate) with the potential for initiation of fatigue failure, near upper hole no. 1 (Table 1). The lowest observed equivalent stress was in the screws $\left(\sigma_{\text {red }}=650 \mathrm{MPa}\right)$.

Fatigue failure stress corresponding to the approx. $10^{4}$ cycles of mastication is $510 \mathrm{MPa}$ for every grade 5 titanium plate. Note, however, that during the healing period, which is initiated at the beginning of mandibular fixation, the bone already begins sharing the load carried by the plate. The distribution of stress shown in the figures in real life after 8400 cycles will not be observed practically due to the completed healing of the fracture. But initially post-operationally, fatigue failure is possible after occlusal loading, which leads to local stress of only approx. $500 \mathrm{MPa}$. This is approx. half as much as typical masticatory forces (for a strut plate positioned upside-down: $915 \mathrm{MPa} / 510 \mathrm{MPa}=1.8$ ) or even in much weaker masti- cation (half as much for the rhombus plate fixed typically: $1155 \mathrm{MPa} / 510 \mathrm{MPa}=2.3)$.

The mean relative displacement of the fracture fragments along the fracture line was measured in 6 models (Table 2). The best fixing method (i.e. the lowest mean relative movement) was reached by the strut plate placed upside-down ( $463 \pm 130 \mu \mathrm{m}$, but stress in the plate is significantly high in that position), next by the rhombus plates with holes that were modified to a round shape (position 4: $467 \pm 172 \mu \mathrm{m}$ ), the rhombus plate with both screws in the oval holes positioned close to the upper border of the holes (position 3: $485 \pm 192 \mu \mathrm{m}$ ) and the rhombus with a mesial screw (screw 4 in Table 1) positioned close to the upper border of the oval hole and the distal screw (screw 3 in Table 1) positioned close to the lower border of the oval hole (position 2: $624 \pm 273 \mu \mathrm{m}$ ). And nearly the same in the rhombus plate screws in position 1 (acc. to manufacturer instructions), i.e. $625 \pm 222 \mu \mathrm{m}$. No statistical significance between all the above was observed. The strut plate fixed in the normal position revealed the worst

Table 2. Stabilization of rigid fixation. Measurements of the condylar fracture fissure after loading (relative displacement)

\begin{tabular}{|c|c|c|c|c|c|c|}
\hline \multirow{3}{*}{$\begin{array}{l}\text { Location of } \\
\text { measurement }\end{array}$} & \multicolumn{6}{|c|}{ Relative displacement } \\
\hline & \multicolumn{2}{|c|}{ strut plate } & \multicolumn{4}{|c|}{ rhombus 3D plate } \\
\hline & normal position & inverted position & screw position 1 & screw position 2 & screw position 3 & screw position 4 \\
\hline Anterior & $570 \mu \mathrm{m}$ & $540 \mu \mathrm{m}$ & $400 \mu \mathrm{m}$ & $270 \mu \mathrm{m}$ & $360 \mu \mathrm{m}$ & $360 \mu \mathrm{m}$ \\
\hline Lateral & $1420 \mu \mathrm{m}$ & $540 \mu \mathrm{m}$ & $560 \mu \mathrm{m}$ & $550 \mu \mathrm{m}$ & $330 \mu \mathrm{m}$ & $330 \mu \mathrm{m}$ \\
\hline Posterior & $1130 \mu \mathrm{m}$ & $570 \mu \mathrm{m}$ & $1020 \mu \mathrm{m}$ & $1100 \mu \mathrm{m}$ & $850 \mu \mathrm{m}$ & $790 \mu \mathrm{m}$ \\
\hline Medial & $870 \mu \mathrm{m}$ & $350 \mu \mathrm{m}$ & $630 \mu \mathrm{m}$ & $650 \mu \mathrm{m}$ & $500 \mu \mathrm{m}$ & $490 \mu \mathrm{m}$ \\
\hline
\end{tabular}

Explanation of tested variants: strut plate in normal position, i.e. recommended by DePuy Synthes; strut plate in inverted position, i.e. upside-down; rhombus plate with screw position 1, i.e. according to KLS Martin recommendation: 2 screws positioned close to the lower border sliding middle holes; rhombus plate with screw position 2, i.e. mesial screw positioned close to the upper border of the sliding hole no. 3 (see Table 1) and distal screw positioned close to the lower border of sliding hole no. 4 (see Table 1); rhombus plate with screw position 3, i.e. both screws in sliding holes positioned close to the upper border of the holes; modified rhombus plate with screw position 4, i.e. where all holes are round. 
statistically confirmed result: $958 \pm 312 \mu \mathrm{m}$ of movement in the fracture line $(\mathrm{F}=6.33, \mathrm{p}<0.001)$. It was the only statistically significant result.

\section{Discussion}

Maximillian Titus Huber published a crucial paper addressing the failure of brittle materials in 1904, and stated the criterion of distortional energy in tension as being important. ${ }^{17}$ He proved that compression of brittle materials did not generally cause failure. Later, Richard von Misses in 1913 and Heinrich Hencky in 1925 published their papers concerning the same topic. ${ }^{18,19}$ Nowadays, the open reduction and rigid fixation (ORIF) in a plate numerical evaluation is possible thanks to them. Although few studies have used the finite element method, ${ }^{20-23}$ the results of in vitro studies are similar in some ways to those found in computational studies, regarding the use of 2 stable titanium miniplates in such fractures. In addition, future clinical trials, applying the methodology with finite elements or not, are postulated to better indicate the most appropriate techniques for osteosynthesis in cases of mandibular condyle fractures. ${ }^{24}$

Moreover, the intense discussion of the best surgical management of condylar is still ongoing, including assortment of the fixing material. Application of positioning lag screws, ${ }^{25}$ which is the predicted method of treatment in high condylar fractures, can have a better prognosis than using a titanium plate and obviously much better than the removal of the condylar fragment. ${ }^{26}$ The technique of the application of 2 strait plates is debatable. ${ }^{27}$ Microplates limit dissection, providing excellent fixation for intracapsular condylar head fractures, provide adequate rigidity for the fixation of condylar neck fractures, yielding excellent functional and radiographic results. Additionally, the rate of complications after microplate fixation is equal to those in the miniplate. ${ }^{28}$ Next, smaller plates can be successfully used with the endoscopic intraoral approach and are suitable for fractures of the lower neck and subcondylar. ${ }^{29}$

ORIF by both investigated plates, and in all plate and screwing positions, achieved higher mean relative movements in the fracture line (4-15 times worse) than the 2 plain plate fixations, ${ }^{27}$ the Medartis 9-hole delta or A-shape plate. ${ }^{8}$ It derives from the weak construction and small dimensions that is the endoscopic dedication compromise. Surprisingly, the fracture fissure has relatively low movement (approx. $0.5 \mathrm{~mm}$ extension when bit; due to the 3 screws used in the proximal fragment) as fixation is done by strut plates screwed upside-down, contrary to the high maximal stress in the plate $\left(\sigma_{\text {red }}=915 \mathrm{MPa}\right)$. It looks as if the slight movement is paid for with high stress in the structure of the endoscopic plate. And the maximal equivalent stress of $915 \mathrm{MPa}$ leads the surgeon to the border of risk (fatigue failure after occlusal loading in the post-operational period). Any adjustments of these 2 plates by bending, flattening or cutting are unsafe in light of the calculations shown here. A reasonable compromise is the rhombus plate with only round holes (cat. no. 25-283-05-09). Its design, despite the small dimensions of the plate, is biomechanically suitable.

With biomechanical considerations, where the stress in real structure connectors, for example fracture line fixation, exceed yield stress, the nonlinear material model should be used. The mechanical properties defined only by Young's modulus and Poission ratio are inadequate in such kind of calculations. The plastic material model is required. The yield point is well known in mechanical problems. This means that the mechanical properties of the material are defined to the yield point only by Young's modulus for an isotropic structure, and by the plastic modulus beyond that point until the ultimate tensile or compression stress. It was found here that the elastic behaviors of 2 variants of rhombus plate fixation transverse to a rather plastic state due to exceeding the yield strength in local points and even ultimate tensile stress significantly (in linear modeling). It is obviously a local problem in the plate, but local foci of plastification risk may initiate gradual plate deformation and displacement of bone fragments during healing.

Undoubtedly, the advantage of both investigated plates is the possibility of endoscopic application, which would be difficult in bigger plates like the lambda, inverted $\mathrm{Y}$ or A-shape. In the case of small "endoscopic" plates (triangle, rhombus), inverted fixation (upside-down) is possible. And sometimes the inverted location is tempting, as 2 horizontal screws would be located in the condylar head and 2 vertical screws in the condylar neck. Validation of the inverted fixation of these plates brings this analysis. In the case of strut plates, it is clearly prohibited due to high stress generation. On another hand, in the case of rhombus one with 2 oval holes, a series of screw positions are possible. Surprisingly, the typically-used lower position of adaptation screws in clinical application leads to risky displacement and increased stress in the plate. The safest fixation in the rhombus plate is reached as one uses a plate with only round holes. The rhombus plate with oval sliding holes should be avoided in clinical applications. Based on the finite element analysis, the manufacturer chronological standard sequence for screw fixing should be changed from 1-2-3-4-5 (Table 1) to 1-2-5(with traction and screwing eccentrically for sliding)-3(in the upper part of the holes, passively)-4(in the upper part of the holes, passively). Then the biomechanical effect will be much better.

The plates tested are dedicated to lower (or intermediate) condylar fractures (contrary to manufacturer information). They cannot be used for high neck fractures. So, it is difficult to refer the FEM results obtained to the plates dedicated for fixation of high condylar fractures. ${ }^{8}$ It seems that a high fracture fixation is a more mechanically challenging objective. ${ }^{30}$ 


\section{Conclusions}

It should be noted, comparing both plates, that the rhombus 3D plate equipped only with round holes presented its superiority within this comparison. It is mechanically relatively resistant and relatively durable in spite of the design being only partially according to compression and traction force propagation in the mandibular condyle. Application of these endoscopic plates is sensitive to the position of screws and requires intermaxillary fixation or an extremely cooperative patient due to the fragility of the fixing material.

\section{References}

1. Puch A, Kurczyński M, Arkuszewski P, Bogusiak K. Overview of emergency department visits in Craniomaxillofacial and Oncological Clinic of Medical University in Lodz. Dent Med Probl. 2016;53:244-252.

2. Gealh WC, Costa JV, FerreiraGM, Iwaki Filho L. Comparative study of the mechanical resistance of 2 separate plates and 2 overlaid plates used in the fixation of the mandibular condyle: An in vitro study. J Oral MaxillofacSurg. 2009;67:738-743.

3. Pilling E, Eckelt U, Loukota R, Schneider K, Stadlinger B. Comparative evaluation of ten different condylar base fracture osteosynthesis techniques. Br J Oral Maxillofac Surg. 2010;48:527-531.

4. Vesnaver A, Ahcan U, Rozman J. Evaluation of surgical treatment in mandibular condyle fractures. J Craniomaxillofac Surg. 2012;40:647-653.

5. DePuy Synthes materials. http://synthes.vo.Ilnwd.net/o16/LLNWMB8/INT\%20Mobile/Synthes\%20International/Product\%20Support\%20Material/legacy_Synthes_PDF/036.001.290.pdf. Accessed September 9, 2017.

6. KLS Martin Products. http://www.klsmartin.com/products/implantsand-implant-systems/cmf/titanium-osteosynthesis/mandibula/ rhombic-3d/?L=2. Accessed September 9, 2017.

7. Pekedis $\mathrm{M}$, Yildiz $\mathrm{H}$. Comparison of fatigue behaviour of eight different hip stems: A numerical and experimental study. J Biomed Sci Engin. 2011;4:643-650.

8. Kozakiewicz M, Świniarski J. "A" shape plate for open rigid internal fixation of mandible condyle neck fracture. J Cranio-Maxillofac Surg. 2014;42:730-737.

9. Mesnard M, Ramos A, Ballu A, Morlier J, Cid M, Simoes JA. Biomechanical analysis comparing natural and alloplastic temporomandibular joint replacement using a finite element model. J Oral Maxillofac Surg. 2011;69:1008-1017.

10. Iwasaki LR, Baird BW, McCall Jr WD, Plickel JC. Muscle and temporomandibular joint forces associated with chin cup loading predicted by ical modeling. Am J Orthod Dentofacial Orthop. 2003;124:530-540.

11. Ramos A, Completo A, Relvas C, Mesnard M, Simoes JA. Straight, semi-anatomic and anatomic TMJ implants: The influance of condylar geometry and bone fixation screws. J Cran Maxilllofac Surg. 2011;39:343-350.

12. Korioth TW, Romilly DP, Hannam AG. Three-dimensional finite element stress analysis of the dentate human mandible. Am J Phys Anthropol. 1992;38:69-96.

13. Motoyoshi M, Ueno S, Okazaki K, Shimuzi N. Bone stress for a mini implant close to the roots of adjacent teeth-3D finite element analysis. Int J Oral Maxillofacial Surg. 2009;38:363-368.

14. Ichim I, Kieser JA, Swain MV. Functional significance of strain distribution in the human mandible under masticatory load: Numerical predictions. Arch Oral Biol. 2012;52:465-473.

15. Field C, Ichim I, Swain MV, et al. Mechanical responses to orthodontic loading: A 3-dimensional finite element multi-tooth model. Am J Orthod Dentofacial Orthop. 2009;135:174-181.

16. Krenkel C. Treatment of mandibular-condylar fractures. Atlas Oral Maxillofac Surg Clin North Am. 1997;5:127-155.

17. Huber MT. Specific deformation work as a measure of material damage. Czas Tech. 1904;22:38-50.
18. Mises R. Mechanik der festen Körper im plastisch - deformablen Zustand. Göttinger Nachrichten. Mathematisch-Physikalische Klasse. Berlin: Weidmannsche Buchhandlung;1913:582-592

19. Hencky $\mathrm{H}$. Über langsame stationäre Stromungen in plastischen Massen mit Rucksicht auf die Vorgänge beim Walzen, Pressen und Ziehen von Metallen. Zeit Math Mech. 1925;5:115-124

20. Lauer G, Pradel W, Schneider M, Eckelt U. A new 3-dimensional plate for transoral endoscopic-assisted osteosynthesis of condylar neck fractures. J Oral Maxillofac Surg. 2007;65:964-971.

21. Parascandolo S, Spinzia A, Parascandolo S, Piombino P, Califano L. Two load sharing plates fixation in mandibular condylar fractures: Biomechanical basis. J Craniomaxillofac Surg. 2010;38:385-390.

22. Seemann R, Schicho K, Reichwein A, Eisenmenger G, Ewers R, Wagner A. Clinical evaluation of mechanically optimized plates for the treatment of condylar process fractures. Oral Surg Oral Med Oral Pathol Oral Radiol Endod. 2007;104:1-4.

23. Wagner A, Krach W, Schicho K, Undt G, Ploder O, Ewers R. A 3-dimensional finite-element analysis investigating the biomechanical behavior of the mandible and plate osteosynthesis in cases of fractures of the condylar process. Oral Surg Oral Med Oral Pathol Oral Radiol Endod. 2002;94:678-686.

24. Costa FWG, Bezerra MF, Ribeiro TR, Pouchain EC, Sabóia VPA, Soares ECS. Biomechanical analysis of titanium plate systems in mandibular condyle fractures. A systematized literature review. Acta Cirúrg Bras. 2012;27:424-429.

25. Kozakiewicz M, Świniarski J. Treatment of high fracture of the neck of the mandibular condylar process by rigid fixation performed by lag screws: Finite element analysis. Dent Med Probl. 2017;54:223-228.

26. Luo S, Li B, Long $X$, Deng $M$, Cai H, Cheng Y. Surgical treatment of sagittal fracture of mandibular condyle using long-screw osteosynthesis. J Oral Maxillofac Surg. 2011;69:1988-1994.

27. Aquilina P, Chamoli U, Parr WCH, Clausen PD, Wroe S. Finite element analysis of three patterns of internal fixation of fractures of the mandibular condyle. Br J Oral Maxillofac Surg. 2013;51:326-331.

28. Xie ST, Singhal D, Chen CT, Chen YR. Functional and radiologic outcome of open reduction and internal fixation of condylar head and neck fractures using miniplate or microplate system. Ann Plast Surg. 2013;71(Suppl. 1):S61-S66.

29. Nogami S, Takahashi T, Yamauchi K, et al. Clinical comparison between the retromandibular approach for reduction and fixation and endoscope-assisted open reduction and internal fixation for mandibular condyle fractures. J Craniofac Surg. 2012;23:1815-1818.

30. Loster JE, Wieczorek A, Ryniewicz WI. Condylar guidance angles obtained from panoramic radiographic images: An evaluation of their reproducibility. Dent Med Probl. 2017;54:35-40. 